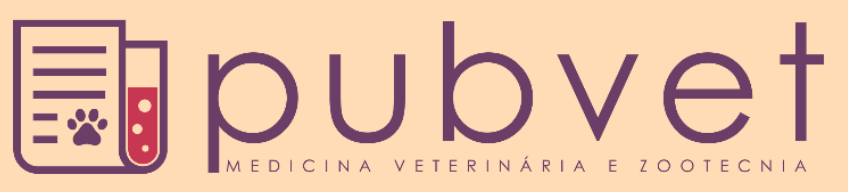

https://doi.org/10.31533/pubvet.v16n02a1026.1-7

\title{
Conhecimento sobre esporotricose entre voluntários de ONGs e protetores independentes de animais do estado de São Paulo
}

\author{
Maria Luíza Pássaro ${ }^{1 * \vartheta}$, Tatiana Franco Sittinieri ${ }^{1}$, Ed Wilson Santos ${ }^{2} \oplus \mathbb{0}$ \\ ${ }^{1}$ Graduanda do curso de Medicina Veterinária, Universidade Anhembi Morumbi, São Paulo Brasil. \\ ${ }^{2}$ Professor da Universidade Anhembi Morumbi, Departamento de Medicina Veterinária. \\ *Autor para correspondência, E-mail: malupassaro@hotmail.com
}

\begin{abstract}
Resumo. A esporotricose é uma doença ocasionada pelo fungo do gênero Sporothrix que acomete diversas espécies animais e seres humanos. E uma zoonose em ascensão no Brasil e o felino doméstico tem grande papel epidemiológico, visto que a transmissão zoonótica vêm crescendo nos últimos anos. Este trabalho teve como objetivo rastrear o conhecimento sobre essa enfermidade entre voluntários de ONGs protetoras de animais e protetores independentes do estado de São Paulo. Supreendentemente, quase metade das pessoas entrevistadas, que trabalham e podem estar expostas a tal zoonose, desconheciam sobre a doença. Mais da metade de voluntários que realizam resgates não usam EPIs adequados ou somente os usam quando o animal é agressivo, reforçando tamanha exposição e vulnerabilidade. Apesar disso, apenas $8 \%$ dos entrevistados relataram já terem apresentado lesões características a da esporotricose, o que mostra que se houvesse maior cautela e conhecimento desse público ao realizar o manejo desses animais, essa incidência poderia ser ainda menor.
\end{abstract}

Palavras-chave: Esporotricose, medicina coletiva, sporothrix, zoonose

\section{Knowledge about sporotrichosis among volunteers of NGOs and independent protectors of animals from the state of São Paulo}

\begin{abstract}
Sporotrichosis is a disease caused by the fungus of the genus Sporothrix that affects several animal species and humans. It is an emerging zoonosis in Brazil and the domestic cat has a great epidemiological role, since zoonotic transmission has been rising in recent years. This work aimed to track knowledge about this disease among volunteers from animal protection NGOs and independent protectors from the state of São Paulo. Surprisingly, almost half of the people interviewed, who work andmay be exposed to such zoonosis, were unaware of the disease. More than half of volunteers who carry out rescues do not use adequate IPE or only use them when the animal is aggressive, reinforcing such exposure and vulnerability. Despite this, only $8 \%$ of participants reported having already presented lesions characteristic of sporotrichosis, which shows that if there was greater caution and knowledge of this public when handling these animals, this incidence could be even lower.
\end{abstract}

Keywords: Shelter medicine, Sporothrix, sporotrichosis, zoonosis

\section{Introdução}

A esporotricose é uma micose sistêmica de grande importância na saúde pública por acometer seres humanos e várias espécies de animais. O agente etiológico é o fungo dimórfico do gênero Sporothrix, mais comumente encontrado nas espécies brasiliensis e schenckii, os quais são onipresentes no solo rico em matéria orgânica, vegetação e árvores (Fraser et al., 1996; Jericó et al., 2015; Little, 2016; Meinerz et al., 2007). Essa doença de distribuição mundial ocorre principalmente em regiões de clima quente e 
úmido. No Brasil são encontrados diversos relatos em pessoas e animais. No Rio de Janeiro, esse fungo foi encontrado em mais de 4.000 pessoas e 3.804 gatos pelo Institutode Pesquisa Clínica Evandro Chagas e Fundação Oswaldo Cruz entre os anos de1998 e 2011 (Gremião et al., 2015; Jericó et al., 2015). O Conselho Regional de Medicina Veterinária do Estado de São Paulo publicou em 2018 que o município de Guarulhos notificou um aumento de 51\% no número decasos de esporotricose em animais de 2016 para 2018, o que reforça a importância dessa enfermidade para saúde única.

Felinos, machos, não castrados e que possuem livre acesso à rua são os mais acometidos e possuem um papel epidemiológico significativo já que a transmissão zoonótica vem crescendo progressivamente nos últimos anos (Lupi et al., 2012). Os hábitos naturais desses animais como os de afiar unhas em árvores, cobrir dejetos com terra e brigas territoriais favorecem a infecção que ocorre, principalmente, através da inoculação traumática do fungo na pele por arranhaduras e mordeduras (Almeida et al., 2018; Cavalcanti et al., 2018; Gremião et al., 2015; Jericó et al., 2015; Lázaro et al., 2008).

Em gatos ocorrem três síndromes clínicas da doença: cutânea localizada, linfocutânea e disseminada, sendo as duas primeiras as mais comuns. As manifestações clínicas mais frequentes são caracterizadas como múltiplas lesões cutâneas, mais comumente localizadas em face, membros e cauda, que podem envolver mucosas, principalmente a nasal, linfadenomegalia também pode estar presente. Pode haver ulceração dos nódulos e produção de secreção sero-sanguinolenta e/ou purulenta, algumas lesões formam crostas e necrose. A forma disseminada da doença deve ser considerada caso o animal apresente letargia, anorexia e febre e os órgãos mais acometidos são pulmão e fígado (Gremião et al., 2021; Larsson, 2011; Little, 2016; Pires, 2017).

Segundo Lupi et al. (2012), pessoas acometidas apresentam o cancro de inoculação no local onde foram arranhados/mordidos que evolui para uma lesão ulcerada de base infiltrada e eritematosa. A partir da lesão inicial, ocorre formação de nódulos indolores ao longo da via linfática, que podem ulcerar e estar associados ao eritema nodoso.

O diagnóstico em felinos pode ser realizado pela visualização de células leveduriformes por citologia e/ou histopatológico, já que esses animais apresentam alta quantidade desses agentes nas lesões, diferentemente do que ocorre nos seres humanos. A cultura micológica de exsudatos e/ou amostras de tecido é considerada diagnóstico definitivo e padrão ouro no diagnóstico dessa enfermidade (Etchecopaz et al., 2021; Gross et al., 2009; Jericó et al., 2015; Lloret et al., 2013; Paterson, 2010; Pereira et al., 2011).

O tratamento em felinos é longo, complexo e de alto custo. O fármaco de escolha é Itraconazol que deve ser administrado via oral por 30 dias após a cura aparente do animal, esse tratamento dura de meses a 1 ano e deve-se atentar-se a recidivas (Barros et al., 2004; Fraser et al., 1996; Little, 2016).

O contato com felinos infectados carrega altíssimo risco zoonótico, por isso é imprescindível que essas pessoas façam uso de luvas e manga comprida ao realizar o manejo desses gatos e isolá-los de outros animais sadios até sua completa cura clínica. A desinfecção do ambiente deve ser realizada com hipoclorito de sódio e os animais que vierem a óbito devem ser destinados corretamente. Tutores também devem ser orientados sobre essa zoonose para que castrem seus gatos e os mantenham domiciliados, diminuindo assim disputas territoriais e, consequentemente, a probabilidade de contaminação (Jericó et al., 2015; Lloret et al., 2013).

O Conselho Regional de Medicina Veterinária do Estado de São Paulo publicou uma cartilha em fevereiro de 2018 onde dizia que há falta de dados e informações oficiais dessa doença, acarretando na dificuldade de planejar ações de vigilância e controle. Sugeriu-se então que os municípios façam a notificação mesmo sem obrigatoriedade.

\section{Material e métodos}

Um total de 111 indivíduos voluntários de ONGs protetoras de animais e protetores independentes do estado de São Paulo foram convidados a responder um questionário no Google Forms para avaliação de seus conhecimentos sobre esporotricose.

A primeira etapa da pesquisa consistia em saber se a pessoa possuía algum conhecimento sobre a doença e se, ao realizar o resgate de gatos, era utilizado algum tipo de proteção como luvas e roupas adequadas, visando a prevenção do contato com algum animal possivelmente infectado. 
$\mathrm{Na}$ etapa seguinte, foram disponibilizadas algumas fotos de animais com lesões características de esporotricose (Foto 1) e a intenção da pergunta era descobrir se o indivíduo já havia entrado em contato com um animal naquela condição, mesmo possuindo ou não conhecimento sobre a doença.

Continuando a pesquisa, fizemos uma lista com possíveis métodos de prevenção da doença, em que o indivíduo poderia assinalar mais de uma alternativa. Entre elas estavam banhos regulares, vacinação, vermifugação e não permitir que gatos tivessem acesso à rua, quintal ou terra.

A etapa final do questionário abordava a transmissão aos seres humanos. Primeiro perguntamos se a esporotricose é uma doença que poderia ser transmitida ao homem e demos algumas opções de como eles acreditavam que poderia ocorrer essa contaminação. Entre as alternativas fornecidas estavam fezes contaminadas, espirros, mordidas e arranhões de animais contaminados e contato direto com o solo contaminado (cada indivíduo poderia assinalar mais de uma alternativa que acreditasse que fosse verdadeira). Para finalizar o questionário, colocamos fotos de lesões típicas de esporotricose em humanos (Foto 2), e indagamos se eles já haviam apresentado alguma lesão parecida.

Todos os dados obtidos a partir do questionário foram usados para medir o conhecimento sobre uma zoonose tão importante e frequente em uma comunidade de pessoas que estão em contato direto com os animais e, consequentemente, com o risco de adquirir tal contaminação. Ao final da pesquisa, disponibilizamos um folheto informativo sobre a doença e os principais meios de prevenção da mesma.

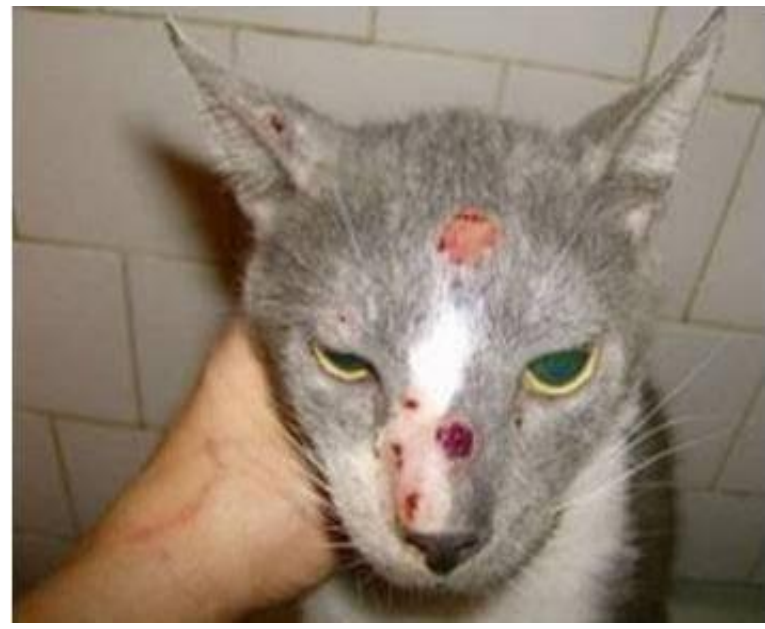

Foto 1. Animal com lesões características de esporotricose Fonte: $\underline{\text { SOS.felino.org.br }}$

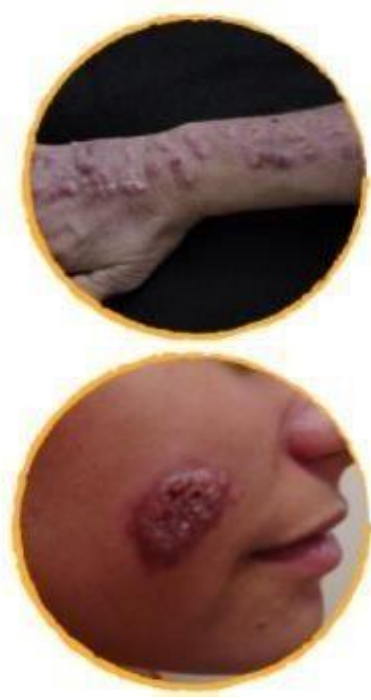

Foto 2 fotos de lesões típicas de esporotricose em humanos. Fonte: sbdri.org.br

\section{Resultados e discussão}

Os resultados da pesquisa revelaram que $41,4 \%$ dos entrevistados não sabiam ou apenas ouviram falar sobre esporotricose. Ou seja, de um universo demográfico de 111 pessoas idealmente em contato potencial com tal zoonose, quase metade das respostas desconheciam um fator de risco primário em sua atividade de voluntariado (Gráfico 1).

Reforçando o que foi publicado na cartilha do CRMV-SP em 2018, a falta de informação contribui para o aumento de casos através da transmissão zoonótica e, consequentemente, dificulta o controle dessa zoonose.

Das 81 pessoas que responderam realizar resgate de gatos, cerca de $27 \%$ responderam que utilizam os EPIs (equipamento de proteção individual) adequados, enquanto $49 \%$ responderam que utilizam apenas quando o animal aparenta agressividade e outros $24 \%$ sequer utilizam alguma proteção (Gráfico 2). Ora, considerando que impossível de antemão determinar com segurança a agressividade dos animais, seguro afirmar que $73 \%$ dos entrevistados expõem-se a riscos não tivemos um resultado aparentemente equilibrado em relação ao contato com gatos possivelmente infectados, sendo que 48,6\% já resgataram ou tiveram contato com algum animal apresentando lesões características de esporotricose, enquanto 51,4\% não tiveram contato (Gráfico 3). 


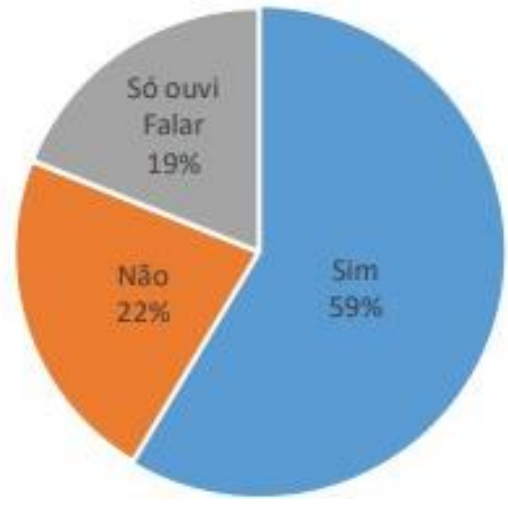

Gráfico 1. Fator de risco primário com a esporotricose em sua atividade de voluntariado

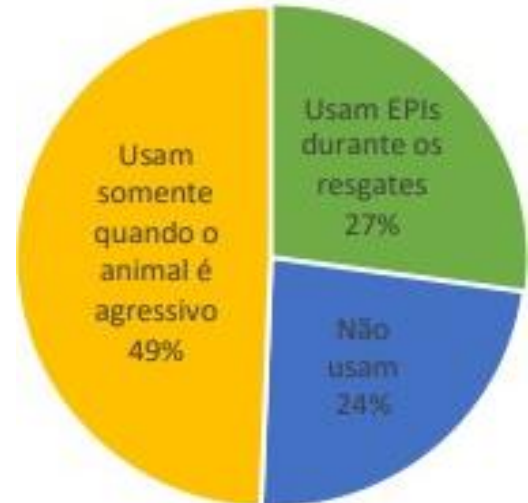

Gráfico 2. Utilização de equipamentos de proteção individual.

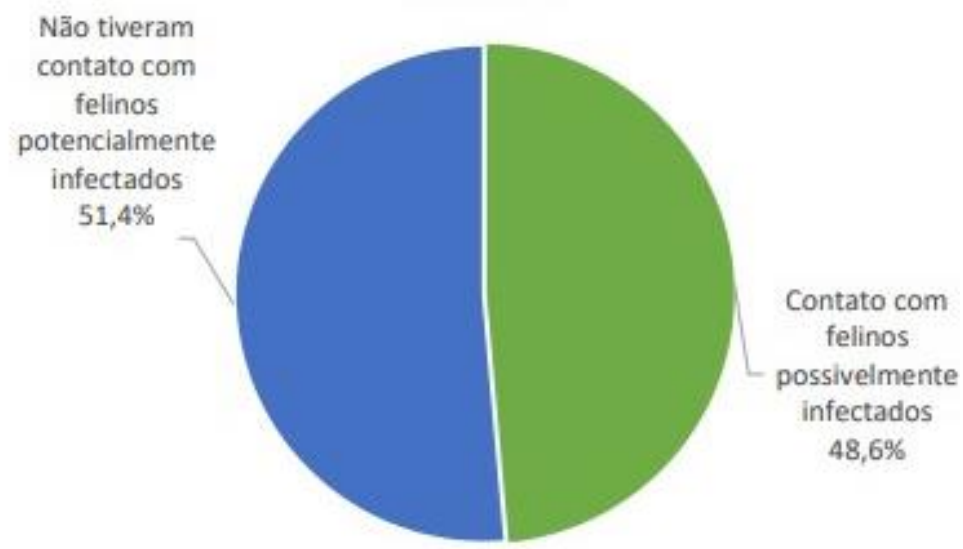

Gráfico 3. Resultado aparentemente equilibrado em relação ao contato com gatos possivelmente infectados com esporotricose.

O uso de luvas e blusas com manga comprida criam uma barreira física, diminuindo assim a exposição do indivíduo e consequentemente as chances de infecção (Scheftel et al., 2010). Contudo, ao considerarmos que $73 \%$ dos entrevistados manejam os animais de forma inadequada nos resgates, notamos o risco que quase metadedas pessoas tiveram quando foram expostas a lesões características dessa zoonose.

Com relação a formas de prevenção contra a esporotricose para os animais, $26,1 \%$ das respostas dos nossos entrevistados desconhecem a melhor maneira de prevenir a doença; $13,5 \%$ acreditam que banhos regulares são uma opção; $27,9 \%$ apostam na vacinação; $16,2 \%$ na vermifugação e $62,2 \%$ acreditam que uma maneira de prevenir a esporotricose é não permitir que os gatos tenham acesso à rua, quintal ou terra (Gráfico 4).

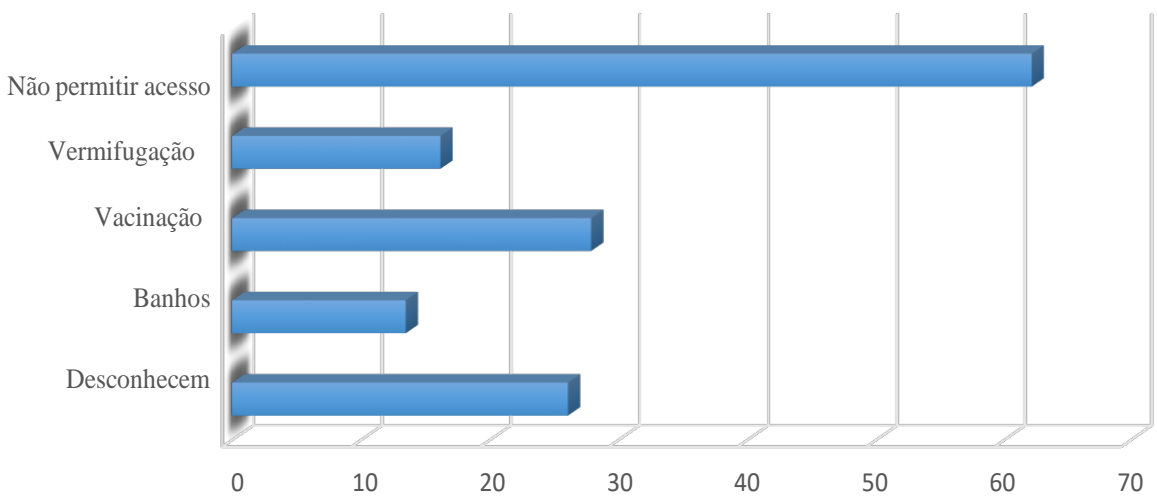

Gráfico 4. Métodos de Prevenção da esporotricose 
Com efeito, apesar de grande parte das respostas se direcionarem a formas inócuas de prevenção (vacina, banho,vermifugação etc), a maior parte dos entrevistados parece reconhecer a vulnerabilidade do animal que tem acesso à rua.

Gatos não totalmente domiciliados ficam susceptíveis a traumas, envenenamento, predação e interagem com outros animais de companhia e/ou animais selvagens. Esse tipo de contato aumenta o risco desses felinos contraírem e transmitirem doenças como bartolenose, esporotricose, toxoplasmose, FIV, FeLV (Loyd et al., 2013; Tan et al., 2020).

Resposta talvez mais surpreendente, a grande maioria dos nossos entrevistados $(84,7 \%)$ tem a consciência de que a esporotricose pode ser transmitida aos seres humanos, mesmo aqueles que desconheciam a própria doença, o que parece denotar um certo viés cognitivo no que se refere a possibilidade transmissional de doenças para humanos.

Quando questionamos quais as possíveis formas de transmissão, 30,6\% das respostas indicavam que fezes contaminadas são uma opção; $21,6 \%$ apostam em espirros de animais contaminados; $51,4 \%$ em mordidas de animais contaminados e 68,5\% e arranhões de animais contaminados. Além disso, $27 \%$ acreditam que o contato com solo contaminado seja uma opção de transmissão também. A maioria das respostas, portanto, revelaram uma percepção real das verdadeiras formas de transmissão da zoonose(Gráfico 5).

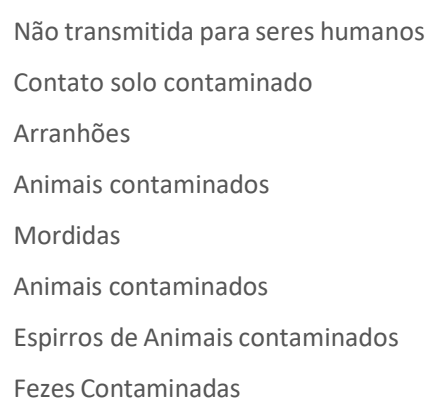

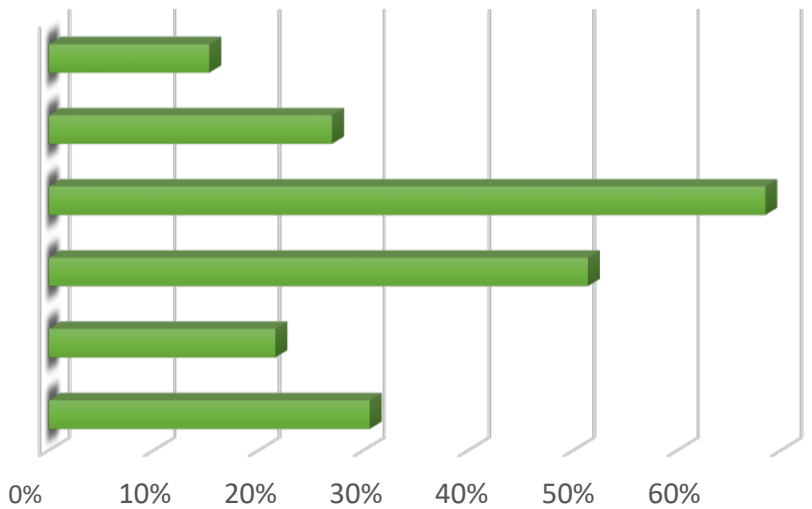

Gráfico 5. Meio de transmissão da esporotricose

Visto que o Sporothrix está presente em solos ricos em matéria orgânica, vegetação e árvores e levando em consideração os hábitos dos felinos (afiar as unhas em árvores e cobrir seus dejetos com terra, por exemplo) fechamos uma importante via de contaminação desses animais. Além da contaminação através do contato com o fungo no ambiente, deve-se lembrar que animais com livre acesso à rua possuem maior risco de se infectarem através de arranhões ou mordeduras durante brigas, brincadeiras ou cópula com outros animais infectados (Cavalcanti et al., 2018).

Finalizando os resultados da pesquisa, $8,1 \%$ dos entrevistados já apresentaram alguma lesão característica de esporotricose. Apesar dessa porcentagem ser relativamente baixa, é importante ressaltar que ela poderia ser consideravelmente menor caso o manejo dos animais fosse corretamente aplicado, além de que uma quantidade considerável de pessoas que lidam diretamente com gatos e consequentemente com o risco de contrair esporotricose, ainda desconhecem muitas informações sobre a doença.

\section{Conclusão}

Perante os resultados obtidos na pesquisa, percebe-se que uma parcela considerável da comunidade que faz o resgate de gatos não se protege da maneira adequada ao realizá-lo. Um simples ato de colocar uma roupa de proteção e usar luvas ao fazer o resgate, já diminui muito a probabilidade de contaminação. Além disso, a conscientização dessa comunidade sobre o manejo adequado de gatos seria essencial para diminuir o número de animais contaminados. $\mathrm{O}$ auxílio de órgãos públicos para divulgação de informações sobre essa tão importante zoonose é imprescindível. 


\section{Referências bibliográficas}

Almeida, A. J., Reis, N. F., Lourenço, C. S., Costa, N. Q., Bernardino, M. L. A., \& Vieira-da-Motta, O. (2018). Esporotricose em felinos domésticos (Felis catus domesticus) em Campos dos Goytacazes, RJ. Pesquisa Veterinária Brasileira, 38(7), 1438-1443. https://doi.org/10.1590/1678-5150-PVB5559

Barros, M. B. L., Schubach, A. O., Valle, A. C. F., Galhardo, M. C. G., Conceição-Silva, F., Schubach, T. M. P., Reis, R. S., Wanke, B., Marzochi, K. B. F., \& Conceiçao, M. J. (2004). Cat-transmitted sporotrichosis epidemic in Rio de Janeiro, Brazil: description of a series of cases. Clinical Infectious Diseases, 38(4), 529-535. https://doi.org/10.1086/381200.

Cavalcanti, E. A. N. L. D., Ignácio, T. C., Kunrath, S. E., Meinerz, A. R. M., Farias, R. O., \& Osório, L. G. (2018). Esporotricose: Revisão. PUBVET, 12, 133.

Etchecopaz, A., Toscanini, M. A., Gisbert, A., Mas, J., Scarpa, M., Iovannitti, C. A., Bendezú, K., Nusblat, A. D., Iachini, R., \& Cuestas, M. L. (2021). Sporothrix Brasiliensis: A Review of an Emerging South American Fungal Pathogen, Its Related Disease, Presentation and Spread in Argentina. Journal of Fungi, 7(3), 170. https://doi.org/10.3390/jof7030170.

Fraser, C. M., Bergeron, J. A., Mays, A., \& Aiello, S. A. (1996). Manual Merck de Veterinária: um manual de diagnóstico, tratamento, prevenção e controle de doenças para o veterinário. Roca.

Gremião, I. D. F., Menezes, R. C., Schubach, T. M. P., Figueiredo, A. B. F., Cavalcanti, M. C. H., \& Pereira, S. A. (2015). Feline sporotrichosis: epidemiological and clinical aspects. Medical Mycology, 53(1), 15-21. https://doi.org/10.1093/mmy/myu061.

Gremião, I. D. F. R., Silva, E. M., Montenegro, H., Carneiro, A. J. B., Xavier, M. O., Farias, M. R., Monti, F., Mansho, W., Pereira, R. H. M. A., \& Pereira, S. A. (2021). Guideline for the management of feline sporotrichosis caused by Sporothrix brasiliensis and literature revision. Brazilian Journal of Microbiology, 52(1), 107-124. https://doi.org/10.1007/s42770-020-00365-3.

Gross, T. L., Ihrke, P. J., Walder, J. E., \& Affolter, K. V. (2009). Doenças de pele do cão e do gato: diagnóstico clínico e histopatológico. Editora Roca.

Jericó, M. M., Kogika, M. M., \& Andrade Neto, J. P. (2015). Tratado de medicina interna de cães e gatos. Guanabara Koogan.

Larsson, C. E. (2011). Esporotricose. Brazilian Journal of Veterinary Research and Animal Science, 48(3), 250-259.

Lázaro, A. P. P., Santos, A. B. S., Murad, A. F., Freitas, B. C. B., Furtado, D. C., Oliveira, I. C. C., Klein, N. F., Coelho, R., Silva, R. S., \& Dias, R. S. R. (2008). Esporotricose pulmonar: relato de caso. Pulmão, 17(2-4), 101-104.

Little, S. E. (2016). O gato: medicina interna. Editora Roca.

Lloret, A., Hartmann, K., Pennisi, M. G., Ferrer, L., Addie, D., Belák, S., Boucraut-Baralon, C., Egberink, H., Frymus, T., \& Gruffydd-Jones, T. (2013). Sporotrichosis in cats: ABCD guidelines on prevention and management. Journal of Feline Medicine and Surgery, 15(7), 619-623.

Loyd, K. A. T., Hernandez, S. M., Abernathy, K. J., Shock, B. C., \& Marshall, G. J. (2013). Risk behaviours exhibited by free-roaming cats in a suburban US town. Veterinary Record, 173(12), 295.

Lupi, O., Belo, J., \& Cunha, P. R. (2012). Rotinas de diagnóstico e tratamento da Sociedade Brasileira de Dermatologia. In Rotinas de diagnóstico e tratamento da Sociedade Brasileira de Dermatologia (p. 533).

Meinerz, A. R. M., Nascente, P. da S., Schuch, L. F. D., Faria, R. O., Antunes, T. de Á., Cleff, M. B., Souza, L. L., Xavier, M. O., Madrid, I. M., \& Meireles, M. C. A. (2007). Felino doméstico como transmissor da esporotricose em trabalhador rural-relato de caso. Arquivos Do Instituto Biológico, 74(2), 149-151.

Paterson, S. (2010). Manual de doenças da pele do cão e do gato. Guanabara Koogan.

Pereira, S. A., Menezes, R. C., Gremiao, I. D. F., Silva, J. N., de O. Honse, C., Figueiredo, F. B., da Silva, D. T., Kitada, A. A. B., dos Reis, E. G., \& Schubach, T. M. P. (2011). Sensitivity of 
cytopathological examination in the diagnosis of feline sporotrichosis. Journal of Ffeline Medicine and Surgery, 13(4), 220-223. https://doi.org/10.1016/j.jfms.2010.10.007.

Pires, C. (2017). Revisão de literatura: esporotricose felina. Revista de Educação Continuada Em Medicina Veterinária e Zootecnia Do CRMV-SP, 15(1), 16-23. https://doi.org/10.36440/recmvz.v15i1.36758.

Scheftel, J. M., Elchos, B. L., Cherry, B., DeBess, E. E., Hopkins, S. G., Levine, J. F., Williams, C. J., Bell, M. R., Dvorak, G. D., \& Funk, R. H. (2010). Compendium of veterinary standard precautions for zoonotic disease prevention in veterinary personnel: National Association of State Public Health Veterinarians Veterinary Infection Control Committee 2010. Journal of the American Veterinary Medical Association, 237(12), 1403-1422.

Tan, S. M. L., Stellato, A. C., \& Niel, L. (2020). Uncontrolled outdoor access for cats: An assessment of risks and benefits. Animals, 10(2), 258.

Histórico do artigo:

Recebido: 14 de outubro de 2021

Aprovado: 18 de novembro de 2021

Disponível online: 17 de fevereiro de 2022
Licenciamento: Este artigo é publicado na modalidade Acesso Aberto sob a licença Creative Commons Atribuição 4.0 (CC-BY 4.0), a qual permite uso irrestrito, distribuição, reprodução em qualquer meio, desde que o autor e a fonte sejam devidamente creditado. 